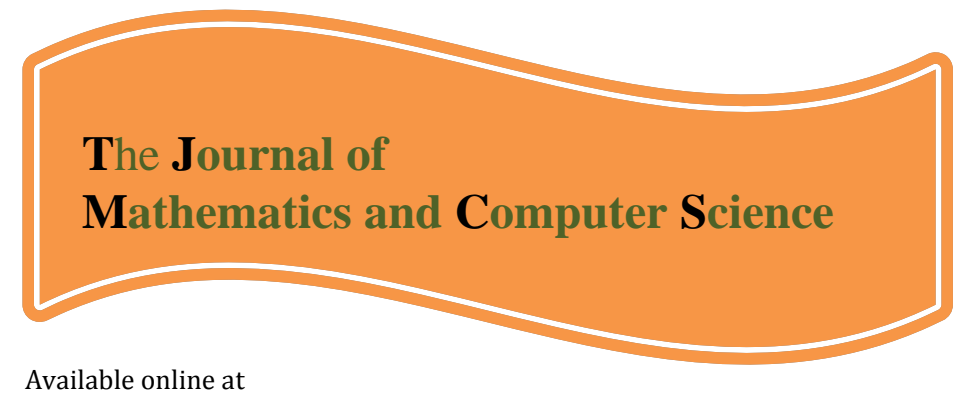

http://www.TIMCS.com

The Journal of Mathematics and Computer Science Vol .2 No.2 (2011) 307-310

\title{
Pattern Recognition By Using Intuitionistic Fuzzy Concepts
}

\author{
Reza Khalesi1,*, Elnaz Babazadeh ${ }^{2}$ \\ Department of Management, Torbatjam Branch, Islamic Azad University, Torbatjam, Iran \\ R.khalesi@sutech.ac.ir \\ Azarbaijan University of Tarbiat Moallem, Elnazbabazadeh@Ymail.com
}

Received: August 2010, Revised: November 2010

Online Publication: January 2011

\begin{abstract}
The most important characteristic of the manager is the ability of decision making and recognition in sensitive situations. Pattern recognition is one of the problems that needs for the high ability of the manager to recognize that the given pattern belongs to what class, among several available classes. In the real world, the information and conditions of the decision making are vague and uncertain. Therefore, we must utilize the uncertain environments. In this paper, we investigate the pattern recognition problems under intuitionistic fuzzy environment, which is a generalization of the fuzzy environment, and represent a new method for it. High efficiency of this method can be extended to other problems similar to handwritten character recognition, fingerprint recognition, human face recognition, classification of X-ray images and thus the manager will persuade to use of it.
\end{abstract}

Keywords: Pattern recognition, Intuitionistic fuzzy, Decision making.

\footnotetext{
1,* Reza Khalesi: Department of Management, Torbatjam Branch, Islamic Azad University, Torbatjam, Iran

2 Azarbaijan University of Tarbiat Moallem
} 


\section{Introduction}

At the first step of this paper, we introduce the concept of an intuitionistic fuzzy set (IFS) and some of preliminaries. Then, by use of these concepts, we propose the new method and investigate the process of pattern recognition.

Since Zadeh introduced fuzzy sets (FSs) theory [1], several new concepts of higher-order FSs have been proposed. Among them, intuitionistic fuzzy sets (IFSs), proposed by Atanassov [2], provide a flexible mathematical framework to cope, besides the presence of vagueness, with the hesitancy originating from imperfect or imprecise information.

Different aspects of IFSs have been used for pattern recognition and decision making, where imperfect facts and imprecise knowledge exist. In the context of pattern recognition, scholars applied similarity measures for IFSs, in order to perform classification ([4], [6]). Intuitionistic fuzzy relations and correlation measures were defined to classification too ([3], [7]).

In this article, we propose a new method, combining the entropy of IFSs and correlation coefficient of IFSs, to classify the given unknown pattern in a pattern recognition problem.

Definition 1. An IFS A in finite nonempty set $\mathrm{X}$, called universe of discourse, is given by

$$
A=\left\{\left\langle x, \mu_{A}(x), v_{A}(x) \mid x \in X\right\rangle\right\}
$$

where $\mu_{A}(x): X \rightarrow[0,1]$ and $v_{A}(x): X \rightarrow[0,1]$ and $0 \leq \mu_{A}(x)+v_{A}(x) \leq 1$. The values $\mu_{A}(x)$ and $v_{A}(x)$ represent, respectively, the membership degree and the nonmembership degree of the element $\mathrm{x}$ to the set $A[2]$.

Definition 2. For an IFS A in the universe of discourse $X=\left\{x_{1}, x_{2}, \ldots, x_{n}\right\}$, we define

$$
\bar{\mu}_{A}=\frac{1}{n} \sum_{i=1}^{n} \mu_{A}\left(x_{i}\right), \bar{v}_{A}=\frac{1}{n} \sum_{i=1}^{n} v_{A}\left(x_{i}\right),
$$

where $\bar{\mu}_{A}, \bar{v}_{A}$ denote the average membership and nonmembership grades of A, respectively.

Definition 3. Let $A$ and $B$ be two arbitrary IFSs in the universe of discourse $X=\left\{x_{1}, x_{2}, \ldots, x_{n}\right\}$. The correlation coefficient of $A$ and $B$ is given by [3]:

$$
\rho_{(A, B)}=\frac{1}{2}\left(\rho_{1}+\rho_{2}\right)
$$

where

$$
\begin{gathered}
\rho_{1}(A, B)=\frac{\sum_{i=1}^{n}\left(\mu_{A}\left(x_{i}\right)-\bar{\mu}_{A}\right)\left(\mu_{B}\left(x_{i}\right)-\bar{\mu}_{B}\right)}{\sqrt{\sum_{i=1}^{n}\left(\mu_{A}\left(x_{i}\right)-\bar{\mu}_{A}\right)^{2} \sum_{i=1}^{n}\left(\mu_{B}\left(x_{i}\right)-\bar{\mu}_{B}\right)^{2}}}, \\
\rho_{2}(A, B)=\frac{\sum_{i=1}^{n}\left(v_{A}\left(x_{i}\right)-\bar{v}_{A}\right)\left(v_{B}\left(x_{i}\right)-\bar{v}_{B}\right)}{\sqrt{\sum_{i=1}^{n}\left(v_{A}\left(x_{i}\right)-\bar{v}_{A}\right)^{2} \sum_{i=1}^{n}\left(v_{B}\left(x_{i}\right)-\bar{v}_{B}\right)^{2}}} .
\end{gathered}
$$

Definition 4. Let $\mathrm{A}$ be an arbitrary IFS in universe of discourse $\mathrm{X}=\left\{x_{1}, x_{2}, \ldots, x_{n}\right\}$. The intuitionistic entropy of $\mathrm{A}$ is defined as follows [5]:

$$
E(A)=\sum_{i=1}^{n}\left(1-\mu_{A}\left(x_{i}\right)-v_{A}\left(x_{i}\right)\right) \text {. }
$$

\section{The process of the pattern recognition by use of the algorithm}

In this section, we present an algorithm by use of the above definitions to recognize and classify the given pattern in the pattern recognition problems.

Suppose we are given $m$ known patterns $P_{1}, P_{2}, \ldots, P_{m}$, which have classifications $C_{1}, C_{2}, \ldots, C_{m}$ respectively. The patterns are represented by the following IFSs in universe of discourse $X=\left\{x_{1}, x_{2}, \ldots, x_{n}\right\}:$

$$
P_{i}=\left\{\left\langle x_{j}, \mu_{P_{i}}\left(x_{j}\right), v_{P_{i}}\left(x_{j}\right) \mid x_{j} \in X\right\rangle\right\}
$$

where $\mathrm{i}=1,2, \ldots \mathrm{m}$ and $\mathrm{j}=1,2, \ldots, \mathrm{n}$. 
An unknown pattern represented by the IFS Q is given as follows:

$$
Q=\left\{\left\langle x_{j}, \mu_{Q}\left(x_{j}\right), v_{Q}\left(x_{j}\right) \mid x_{j} \in X\right\rangle\right\}
$$

Our aim is to classify $\mathrm{Q}$ to one of the classes $C_{i}(\mathrm{i}=1,2, \ldots, \mathrm{m})$. We use the following formula to obtain entropy weights for the elements of $\mathrm{X}$ :

$$
w_{j}=\frac{1-H_{j}}{n-\sum_{j=1}^{n} H_{j}}
$$

where $w_{j} \in[0,1], \sum_{j=1}^{n} w_{j}=1, H_{j}=\frac{1}{m} E\left(x_{j}\right)=\frac{1}{m} \sum_{i=1}^{m}\left(1-\mu_{P_{i}}\left(x_{j}\right)-v_{P_{i}}\left(x_{j}\right)\right)$ and $0 \leq H_{j} \leq 1,(\mathrm{j}=1,2, \ldots, \mathrm{n})$.

Based on the entropy theory, if the entropy value for each element is smaller across patterns, it should persuade decision makers that such an element should be evaluated as a bigger weight; otherwise, such an element will be judged unimportant by most decision makers.

By use of the equation (3), the correlation coefficient between the pattern $P_{i}$ and the given pattern $\mathrm{Q}$ with entropy weights for elements can be measured by the new formula where defined as follows to calculate the weighted correlation coefficient $W_{i}(\mathrm{i}=1,2, \ldots, \mathrm{m})$ between a pattern $P_{i}$ and the given pattern Q:

$$
W_{i}\left(P_{i}, Q\right)=\frac{1}{2}\left(\rho_{1}\left(P_{i}, Q\right)+\rho_{2}\left(P_{i}, Q\right)\right)
$$

where

$$
\begin{aligned}
& \rho_{1}\left(P_{i}, Q\right)=\frac{\sum_{j=1}^{n} w_{j}\left(\mu_{P_{i}}\left(x_{j}\right)-\bar{\mu}_{P_{i}}\right)\left(\mu_{Q}\left(x_{j}\right)-\bar{\mu}_{Q}\right)}{\sqrt{\sum_{j=1}^{n} w_{j}\left(\mu_{P_{i}}\left(x_{j}\right)-\bar{\mu}_{P_{i}}\right)^{2} \sum_{j=1}^{n} w_{j}\left(\mu_{Q}\left(x_{j}\right)-\bar{\mu}_{Q}\right)^{2}}}, \\
& \rho_{2}\left(P_{i}, Q\right)=\frac{\sum_{j=1}^{n} w_{j}\left(v_{P_{i}}\left(x_{j}\right)-\bar{v}_{P_{i}}\right)\left(v_{Q}\left(x_{j}\right)-\bar{v}_{Q}\right)}{\sqrt{\sum_{j=1}^{n} w_{j}\left(v_{P_{i}}\left(x_{j}\right)-\bar{v}_{P_{i}}\right)^{2} \sum_{j=1}^{n} w_{j}\left(v_{Q}\left(x_{j}\right)-\bar{v}_{Q}\right)^{2}}} .
\end{aligned}
$$

The larger the value of weighted correlation coefficient $W_{i}$, the better the class $C_{i}$, because the given pattern $Q$ is closer to class $C_{i}$. It is obvious that $-1 \leq W_{i}\left(P_{i}, Q\right) \leq 1$ and if $P_{i}=Q$ then $W_{i}\left(P_{i}, Q\right)=1(i=$ $1,2, \ldots, m)$ and $W_{i}\left(P_{i}, Q\right)=W_{i}\left(Q, P_{i}\right)$. According to this, the given pattern can be recognized so that the best class can be selected.

\section{Example}

Suppose we are given 3 known patterns $P_{1}, P_{2}, P_{3}$, which have classifications $C_{1}, C_{2}, C_{3}$ respectively. The patterns are represented by the following IFSs in the universe of discourse $X=\left\{x_{1}, x_{2}, x_{3}\right\}$ :

$$
\begin{aligned}
& P_{1}=\left\{\left\langle x_{1}, 1,0 \mid x_{1} \in X\right\rangle,\left\langle x_{2}, 0.8,0 \mid x_{2} \in X\right\rangle,\left\langle x_{3}, 0.7,0.1 \mid x_{3} \in X\right\rangle\right\} \\
& P_{2}=\left\{\left\langle x_{1}, 0.8,0.1 \mid x_{1} \in X\right\rangle,\left\langle x_{2}, 1,0 \mid x_{2} \in X\right\rangle,\left\langle x_{3}, 0.9,0 \mid x_{3} \in X\right\rangle\right\} \\
& P_{3}=\left\{\left\langle x_{1}, 0.6,0.2 \mid x_{1} \in X\right\rangle,\left\langle x_{2}, 0.8,0 \mid x_{2} \in X\right\rangle,\left\langle x_{3}, 1,0 \mid x_{3} \in X\right\rangle\right\}
\end{aligned}
$$

where $i=1,2, \ldots m$ and $j=1,2, \ldots, n$.

Given an unknown pattern $\mathrm{Q}$ represented by the IFS

$$
Q=\left\{\left\langle x_{1}, 0.5,0.3 \mid x_{1} \in X\right\rangle,\left\langle x_{2}, 0.6,0.2 \mid x_{2} \in X\right\rangle,\left\langle x_{3}, 0.8,0.1 \mid x_{3} \in X\right\rangle\right\}
$$

By using equation (9) entropy weights $w_{j}(\mathrm{j}=1,2,3)$ can be calculated as follows:

$w_{1}=0.325, w_{2}=0.350$ and $w_{3}=0.325$, respectively.

By applying equations (2), (11), (12), (10), respectively, we can compute $\bar{\mu}_{P_{i}}, \bar{v}_{P_{i}}, \rho_{1}\left(P_{i}, Q\right)$ and $\rho_{2}\left(P_{i}, Q\right)$ to obtain $W_{i}\left(P_{i}, Q\right)(\mathrm{i}=1,2,3)$ as follows:

$$
W_{1}\left(P_{1}, Q\right)=-0.5226, W_{2}\left(P_{2}, Q\right)=0.5853, W_{3}\left(P_{3}, Q\right)=0.920575 \text {. }
$$

One can observe that $\mathrm{Q}$ has correctly being classified to $C_{3}$, a result which in agreement with the ones obtained in ([4],[6]).

\section{Conclusion}

In this paper the pattern recognition problems were investigated with a new approach that is more precise and reasonable in comparison with similar methods deal with situations that information about problem are represented by intuitionistic fuzzy sets. Flexibility and high efficiency of this method is useful to deal with vague situations. This method can be extended to other problems similar to handwritten 
character recognition, fingerprint recognition, human face recognition, classification of X-ray images and thus the manager will persuade to use of it.

\section{References}

[1] Zadeh, L. A., "Fuzzy sets", Information and Control, Vol. 8, pp. 338-353, 1965.

[2] Atanassov, K., "Intuitionistic fuzzy sets", Fuzzy Sets and Systems, Vol. 20, pp. 87-96, 1986.

[3] Hung, W. L., "Using statistical viewpoint in developing correlation of intuitionistic fuzzy sets", Internationaljjournal of Uncertainty, Fuzziness and Knowledge- Based Systems, Vol. 9, pp. 509-516, 2001.

[4] Dengfeng, L., and Chuntian,C., "New similarity measures of intuitionistic fuzzy sets and application to pattern recognitions", Pattern Recognition Letters, Vol. 23, pp. 221-225, 2002.

[5] Burillo, P., and Bustince, H, " Entropy on intuitionistic fuzzy sets and on intervalvalued fuzzy sets", Fuzzy Sets and Systems, Vol. 19, pp. 305-316, 1996.

[6] Mitchell, H.B., "On the Dengfeng-Chuntian similarity measure and its application to pattern recognition", Pattern Recognition Letters, Vol. 24, pp. 3101-3104, 2003.

[7] Gerstenkorn, T., and Manko, J., "Correlation of intuitionistic fuzzy sets", Fuzzy Sets and Systems, Vol. 44, pp. 39-43, 1991. 